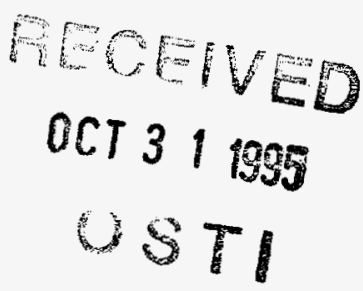

\title{
OPTIMIZATION OF MICROWAVE HEATING IN AN EXISTING CUBICLE CAVITY BY INCORPORATING ADDITIONAL WAVE GUIDE AND CONTROL COMPONENTS
}

RFP-4985

APRIL 1995

Prepared By:

R. R. Erle

V. G. Eschen

G. S. Sprenger

Microwave Vitrification Engineering Team

Rocky Flats Environmental Technology Site

Golden, Colorado 80402-0464

\section{DISCLAIMER}

\begin{abstract}
This report was prepared as an account of work sponsored by an agency of the United States Government. Neither the United States Government nor any agency thereof, nor any of their employees, makes any warranty, express or implied, or assumes any legal liability or responsibility for the accuracy, completeness, or usefulness of any information, apparatus, product, or process disclosed, or represents that its use would not infringe privately owned rights. Reference herein to any specific commercial product, process, or service by trade name, trademark, manufacturer, or otherwise does not necessarily constitute or imply its endorsement, recommendation, or favoring by the United States Government or any agency thereof. The views and opinions of authors expressed herein do not necessarily state or reflect those of the United States Government or any agency thereof.
\end{abstract}




\section{DISCLAIMER}

Portions of this document may be illegible in electronic image products. Images are produced from the best available original document. 


\section{Introduction}

The use of microwave energy to thermally treat Low Level (LLW), Transuranic (TRU), and mixed waste has been under development at the Rocky Flats Environmental Technology Site (Site) since 1986. During that time, the technology has progressed from bench-scale tests, through pilot-scale tests, and finally to a full-scale demonstration unit. Experimental operations have been conducted on a variety of non-radioactive surrogates and actual radioactive waste forms. Through these studies and development efforts, the Microwave Vitrification Engineering Team (MVET) at Rocky Flats has successfully proven the application of microwave energy for waste treatment operations.

In the microwave solidification process, microwave energy is used to heat a mixture of waste and glass frit to produce a vitrified product that meets all the current acceptance criteria at the final disposal sites. All of the development to date has utilized a multimode microwave system to provide the energy to treat the materials. Currently, evaluations are underway on modifications to the full-scale demonstration system that provide a single-mode operation as a possible method to optimize the system. This poster presentation describes the modifications made to allow the single-mode operation.

\section{Waste Forms Amenable to Microwave Solidification}

The development work to date has concentrated on treating the by-pass sludge produced in a hydroxide precipitation process. Tests have been performed on other waste forms that include the following:

\section{Glass Raschig Rings}


2. Miscellaneous Laboratory Glasses

3. Recycled Glass

4. Activated Carbon

5. Remediation Soils

6. Sludge from Solar Evaporation Ponds

7. Incinerator Ash

By combining the above listed wastes in certain ratios (the various glass wastes can be used as silica sources for the vitrification process), it is possible to achieve up to $100 \%$ waste loading in the final waste form. As a result, the amount of waste material contained per unit volume in the final waste form is increased substantially which reduces waste disposal costs.

These waste materials exist in significant quantities as legacy wastes in the DOE Complex and in private sector industry. Additionally, the microwave solidification technology has application potential in foreign waste treatment markets.

\section{Major Advantages of the Microwave Solidification System}

One of the major advantages of the microwave solidification system is that installation in a glove box or remote hot cell is easily accomplished. No moving mechanical parts, refractory materials, or electrodes are required inside the containment structure. This characteristic of the system's design reduces failure points and simplifies maintenance operations.

Another advantage is that the final product is a stable, inert material that is resistant to radiation damage and leaching in contact with ground water. The final waste form is void of hydrogenous material, such as water, organics, or plastic. This eliminates the 
possibility of hydrogen generation in the final waste package which could pose a danger due to container pressurization or explosion. Additionally, volume reductions of up to 3 to 1 are achieved which results in lower transportation and disposal costs.

\section{Recent Modifications to the System}

The system that is upgraded is a multi-mode, $60 \mathrm{~kW}, 915 \mathrm{MHz}$ microwave unit that directly heats to a molten state, a mixture of by-pass sludge and glass formers in a 30 gallon stainless steel drum (applicator). The mixture is fed continuously into the drum while melting is accomplished. Originally, the generator controls were limited to manual operation and could not be automated.

The incorporation of directional couplers, " $\mathrm{N}$ " transitions, a dummy water load connected to a wave-guide diverter switch, an automatic tuner, a gas barrier, a mode converter, additional arc detectors, and a streamlined conduit section passing through the cubicle cavity, allows for improved efficiency in the heating system.

The wave-guide components, including straight and mitered sections, are fabricated to the requirements of the Electronics Industry Association Standards (EIA) for the WR 975 size. The components are fabricated of relatively precise fit-up and with internal finishes that minimize electrical losses.

The " $\mathrm{N}$ " transition sections and dummy water load component are used to monitor the system for forward and reflected power, under instrumentation and full generated $(0$ to $60 \mathrm{~kW}$ ) power levels.

The automatic tuner is a fully computerized "bucket" type, which provides continuous dynamic adjustment to the preferred ratio of forward power-to-reflected power. This 
provides correction for varying process material characteristics (temperature, melting state, and surface position).

The gas barrier is a rectangular flanged window that separates the automatic tuner and wave-guide sections from the processing media, which will include dust and hazardous constituents. The window is designed with a nitrogen gas "sweep", on the process side of the glass, to maintain a dust free surface.

The mode converter is a section that geometrically and electrically changes the generated rectangular electric field mode (TE01) to the preferred circular mode (TM01). The TM01 mode closely matches the drum cross-section, both geometrically and thermally.

Arc detectors are strategically located in the transmission wave-guide and components to automatically shut down the generator when arcing occurs. The process materials heated in the system are susceptible to creating dust when conveyed, and the particles so produced are seeds for arcing.

The streamlined cylindrical section is incorporated to establish a smooth transition from the geometry of the WR 975 wave-guide to the diameter of the drum. The section is installed in the existing cubicle cavity, to bridge the inlet and applicator choke ports. The design of the new section allows for change-over between single and multi-mode conditions as desired.

\section{Benefits to the Up-graded Design}

As stated earlier, the concept of microwave solidification has been proven to be a viable method for treating radioactive, hazardous, and mixed waste materials. The dem- 
onstration system originally designed and operated at the Site produced a product that met all applicable criteria for shipping and disposal at an internment facility. However, the original wave transmission system generated a multi-mode energy pattern that was uncontrollable and produced an unpredictable interference pattern in the processing drum. This resulted in processing rates that were inconsistent. In fact, "dead zones," where heating slowed significantly, were observed at certain waste levels in the drum. Additionally, the wave configuration was such that only the center of the waste surface was heated while the bulk of the waste was heated by thermal conduction. This is highly inefficiently due to the low thermal conductivity of glass materials.

The current efforts of the MVET are focused on optimizing the operation to achieve higher process efficiency and cost effectiveness. The up-grades have contributed significantly to this optimization primarily through two mechanisms; mode control and dynamic tuning. The mode being selected and launched into the melting drum is of an annual shape which increases the surface area of waste being heated. This reduces reliance on thermal conduction to heat the perimeter of the drum. This increases the efficiency of the operation by providing a more even energy distribution and thermal profile on the waste surface. Tuning the wave in the drum allows for maximum energy deposition at any waste level in the drum. This eliminates dead-zones during processing.

Other up-grades to the system were incorporated to increase diagnostic and data acquisition capabilities. This allows for improved system calibration and a strengthened certification package for the final waste form. Automatic "arc" detection and extinguishing capabilities were also added to the system. Arcing can cause damage to the wave generation and transmission system and must be avoided whenever possible. 
To date, these improvements have resulted in more rapid melting and increased the processing rate by 100 to 200 percent. Investigations continue into further process improvements and towards quantifying the operational reliability of the new system configuration. 